\title{
REFLEXIONES SOBRE LO "NUEVO" DEL "NUEVO ORDEN MUNDIAL"*
}

\section{Roberto Russell}

\begin{abstract}
Para abordar desde distintas perspectivas la realidad del "nuevo orden mundial", en primer lugar se realizan algunas aclaraciones del concepto orden mundial. El autor intenta desarrollar esquemáticamente algunas ideas que aporten elementos para el debate actual en América Latina sobre las transformaciones del sistema internacional, centrándose en tres macrocuestiones: qué rasgos tiene este nuevo orden y sus diferencias respecto al de la Guerra Fría; cuáles son sus escenarios probables; $y$, el impacto de los cambios en las bases del orden global sobre la naturaleza de las relaciones internacionales. Concluye que el mapa geopolítico actual no constituye sólo una confrontación entre fuerzas de integración y de fragmentación, sino que a esto hay que sumar las inconsistencias de la brecha temporal entre los cambios de las bases del orden global y las posibilidades reales de adoptar políticas acordes con ellos, brecha que existe y da la razón a quienes dicen que no habrá nada nuevo en el "nuevo orden mundial".
\end{abstract}

\section{El "nuevo orden mundial": aclaraciones necesarias.}

Según se sabe, las referencias a un "nuevo orden mundial" son de antigua data. Toda mención de este tema nos remite rápidamente a Woodrow Wilson y a la fracasada Sociedad de las Naciones. Aunque con otro contenido, la noción de un nuevo orden estuvo también presente durante los años de la detente. Debe recordarse que en su primer mensaje acerca del "estado del mundo" Nixon expresó su satisfacción por el inicio de una "nueva era" en las relaciones internacionales. Desde una óptica diferente, la administración Carter, por su parte, basó sus primeras políticas conforme a una visión que sostenía que el orden mundial transitaba hacia una era de interdependencia en la que las transacciones económicas y los asuntos del mundo industrializado y entre Occidente y los países del denominado Sur definirían las escenas cruciales de la política mundial y que, por

\footnotetext{
* Trabajo preparado para el Seminario organizado por FLACSO/Argentina sobre "La política exterior argentina en la post-Guerra Fría", Buenos Aires, 12 y 13 de marzo de 1992.
} 
tanto, la rivalidad entre Estados Unidos y la Unión Soviética estaba condenada a perder sostenidamente relevancia. $Y$ hoy, el concepto orden mundial vuelve a estar en boca de todos desde que Bush se refiriera al mismo al estallar la crisis del Golfo. Se sabe también que a lo largo de este siglo la expresión nuevo orden fue utilizada en algunos países europeos para indicar el inicio de una etapa venturosa en la historia de la humanidad. En cada caso, la noción orden mundial menciona cosas diferentes, razón por la cual se ha prestado a confusiones.

A fin de sortear el problema conceptual que suele rodear a la expresión orden mundial, me parece de interés efectuar un par de aclaraciones introductorias. En primer lugar, es preciso destacar que la expresión tal como la utilizara el Presidente Bush y que luego recorriera el mundo, encierra un conjunto de supuestos que emanan de la tradición política e intelectual conocida como internacionalismo liberal en los Estados Unidos. Esta tradición, que se nutre de varias vertientes de la filosofía política, cree en la necesidad del liderazgo de las democracias occidentales para la construcción de un orden mundial pacífico basado en la cooperación multilateral y en organizaciones internacionales efectivas. ${ }^{1}$ Sostiene que el logro de ese orden requiere el cumplimiento de tres condiciones básicas: la implantación de regímenes democráticos a escala planetaria; la realización de acuerdos entre naciones para mantener la seguridad colectiva y castigar a los eventuales agresores; $y$, finalmente, el funcionamiento de una economía liberal, esto es de condiciones que hagan posible el comercio entre las naciones y, por tanto, la especialización global.

Aunque tienen puntos de contacto, es necesario diferenciar $-\mathrm{y}$ aquí va mi segunda aclaración- esta visión internacionalista liberal del orden mundial tanto del concepto mismo orden mundial, tal como lo ha desarrollado la literatura especializada en relaciones internacionales, como de las asíllamadas políticas de orden mundial.

Ciertamente, existen varias definiciones sobre lo que se entiende (o debería entenderse) por orden mundial. Tradicionalmente esta noción se ha utilizado para denotar una determinada distribución global de poder entre las principales unidades políticas de una era. En palabras de Aron, para señalar "la configuración de las relaciones de fuerzas entre los actores". Del mismo modo, aunque desde una

\footnotetext{
${ }^{1}$ Ver Richard N. Gardner, "The Comeback of Liberal Internationalism", The Washington Quarterty, Verano 1990, vol. 3, N23, p. 23.
} 
perspectiva que combina realismo clásico con materialismo histórico, Cox considera a los "órdenes mundiales" como estructuras históricas sucesivas en las que interactúan tres categorías de fuerzas: atributos materiales de poder, ideas e instituciones. Como lo explica en un conocido artículo, el término es utilizado en plural para indicar que patrones particulares de relaciones de poder que han perdurado en el tiempo pueden ser contrastados en términos de sus principales características como órdenes mundiales distintivos. ${ }^{2}$ El vocablo orden designa entonces la configuración de las relaciones de fuerzas en una estructura histórica específica. Esta estructura no determina las acciones en forma directa y mecánica, pero sí las condiciona de manera importante. Según lo indica el fundador de la vertiente estructural de la escuela realista: "Los actores y los organismos actúan, los sistemas en su conjunto no lo hacen. Pero las acciones de los actores y de los organismos son afectadas por la estructura del sistema". ${ }^{3} \mathrm{La}$ palabra mundial, por su parte, indica los límites geográficos dentro de los cuales se desarrollan esas interacciones. Hoy, al igual que en la etapa de la Guerra Fría, el orden abarca todo el planeta, pero en otros órdenes anteriores del "mundo" de las interacciones era mucho más limitado, por ejemplo, al Mediterráneo o China. ${ }^{4}$

Para otros autores, en cambio, el término orden mundial designa tanto una condición como un conjunto de procesos. En la opinión de Hoffmann: "El orden mundial es, o, mejor dicho sería, el estado en el que se refrenan la violencia y las crisis económicas; es o sería un estado de moderación entre los actores... Es también todos aquellos procesos de negociación y de disuasión, de equilibrio de fuerzas y de manejo de los vínculos económicos que pueden conducir a ese estado". 5 Desde esta perspectiva, el término no se identifica con el "triunfo universal de una filosofía política en particular" (tal como lo hace el internacionalismo liberal o como lo hacía el marxismo en la versión oficial de los socialismos reales), sino con la posibilidad de

\footnotetext{
${ }^{2}$ Ver "Social Forces, States and World Orders: Beyond International Relations Theory", en: Keohane, Robert O. (ed.), Neorealism and its Critics, (Nueva York: Columbia University Press, 1986), pp. 218-249.

${ }^{3}$ Kenneth Waltz, Theory of Intemational Politics, (Nueva York: Random House, 1979), p. 74.

${ }^{4} \mathrm{Al}$ referirse al universo geográfico del nuevo orden, algunos analistas han mencionado con algo de ironía y también de verdad que el mismo sólo incluiría medio "munđo". Ver, por ejemplo, el número del 23 de febrero de 1991 de la revista The Economist donde se señala en página 46 que: "El "nuevo orden" que el Sr. Bush procura ordenar es bastante pequeño. Incluye Europa, el Medio Oriente, partes de Asia, Canadá y México".

${ }^{5}$ Stanley Hoffmann, Primacy or World Order, American Foreign Policy since the Cold War, (Nueva york: Mc Graw Hill, 1978), p. 188.
} 
hacer viable la coexistencia y la cooperación entre actores que sustentan valores y convicciones diferentes.

En la concepción de Hoffmann el proceso de orden mundial debe ser evolutivo y la palabra orden no es una fórmula para manejar el statu quo sino para la profunda y gradual transformación de la política mundial y, por tanto, también de la política interna. ${ }^{6}$ Sería entonces el resultado de una vasta serie, prácticamente inagotable, de pasos y medidas. Un subproducto y no un objetivo directo, aunque debería ser el último objetivo. ${ }^{7}$

Por último, cabría incluir otra forma de concebir $\rightarrow$ acaso mejor de observar-el orden mundial. Se trataría de considerar no tanto la configuración visible de las relaciones de fuerzas o los resultados manifiestos de los procesos, sino antes bien lo que se ha denominado los cimientos (underpinnings) del orden global -esto es la compleja dinámica que subyace al y determina el comportamiento de los actores-. Para un autor como Rosenau, por ejemplo, estos cimientos incluyen la viabilidad del principio de la soberanía, el surgimiento de nuevos tipos de actores y la capacidad de los Estados de manejarlos y controlarlos, las orientaciones básicas de los organismos y de las personas respecto de la naturaleza de la autoridad y las aptitudes a través de las cuales los ciudadanos y los funcionarios ejercen sus responsabilidades y participan en los asuntos mundiales. ${ }^{8}$ Según la opinión de este autor, estos cimientos de la política mundial han experimentado una profunda transformación por primera vez desde el período que culminó en el Tratado de Westfalia de 1648, aun cuando mucho de la escena actual parece tan sólo un nuevo pliego de la historia de siempre. El problema es que los cambios de cimientos son difíciles de apreciar dado que existiría un time lag entre esos cambios y su reflejo "en los resultados que comprenden las rutinas cotidianas y las crisis de la política mundial". ${ }^{9}$ Sin embargo, se supone que los cambios de cimientos darán lugar, ineludiblemente, a la emergencia de un nuevo orden global cualitativamente distinto a todos los hasta ahora conocidos.

\footnotetext{
${ }^{6}$ Ibid, p. 189.

${ }^{7}$ Ibid.

${ }^{8}$ James N. Rosenau, "The New Global Order. Underpinnings and Outcomes", trabajo presentado en el XV Congreso Internacional de la Asociación Internacional de Ciencia Política, Buenos Aires, 24 de julio, 1991, p. 3.

${ }^{9}$ Ibid.
} 
He apelado a estas tres concepciones de orden mundial -como configuración de fuerzas, como condición y conjunto de procesos, y como underpinnings-porque me parece que cada una de ellas ofrece elementos de utilidad para abordar desde distintas perspectivas las numerosas caras de la realidad del "nuevo orden mundial". La primera definición sirve para orientar la búsqueda de las nuevas relaciones de poder entre los actores y para identificar el "marco para la acción externa" ${ }^{10}$ con sus límites y oportunidades. También, para comparar los rasgos de la estructura histórica de la Guerra Fría con los del orden actual. La segunda y tercera, resultan imprescindibles para adentrarse en cuestiones que tienen que ver con dos temas fundamentales: los escenarios futuros y la continuidad o cambio de naturaleza en las relaciones internacionales. Cabe señalar, asimismo, que las tres concepciones entienden con propiedad que el término orden mundial abarca analíticamente dos realidades diferentes: el medio interestatal, que se refiere a las relaciones entre Estados, y la sociedad transnacional, que comprende las relaciones establecidas y desarrolladas a través de las fronteras estatales entre los individuos y los grupos y en las que también participan (o pueden participar) actores estatales. Es claro que la condición previa para el desarrollo de la sociedad transnacional es "el consentimiento de los gobiernos de dejar que una parte de la vida económica, científica e intelectual escape a su control y se organice por sí misma, dentro y fuera, en formas relativamente autónomas". 11

Finalmente, es preciso distinguir el concepto orden mundial de las políticas de orden mundial, que tienen mucho que ver con el orden como condición y conjunto de procesos a los que se refiere Hoffmann en su definición arriba citada y con los nuevos cimientos de Rosenau. La política de orden mundial, en oposición a la política como de costumbre, se basa (o debería basarse) en un conjunto de principios, normas y procedimientos destinados a zanjar disputas, administrar programas, distribuir recursos y enfrentar problemas o amenazas que por su propia naturaleza no pueden ser resueltos o atacados en forma individual por ningún Estado por más poderoso que sea. Como es obvio, la política de orden mundial constituye un imperativo del orden mundial en el sentido de Hoffmann, dado que su objetivo es desplazar al medio internacional en la dirección de los sistemas

\footnotetext{
${ }^{10}$ Marco para la acción equivale aquí a estructura histórica en el sentido đe Cox.

${ }^{11}$ Stanley Hoffmann, "¿Existe un orden internacional?", Jano y Minerva. Ensayos sobre la guerra y la paz, (Buenos Aires: Grupo Editor Latinoamericano, 1991), p. 95.
} 
políticos internos, "en alejarlo del modelo de Hobbes acercándolo al de la fantasía histórica de Kant". ${ }^{12}$ En el mismo sentido, y apelando nuevamente a los cambios de cimientos, Rosenau sostiene que: "El mundo se ha convertido en algo demasiado complejo y dinámico como para que la independencia pueda satisfacer necesidades y deseos. En cambio hay un amplio reconocimiento en el nivel de las ideas en el sentido de que las necesidades y deseos tienen que ser satisfechos mediante acuerdos recíprocos con otros y que no es contradictorio mantener al mismo tiempo relaciones autónomas e interdependientes en el sistema global". ${ }^{13}$

Dicho esto, es claro que una discuisión seria sobre el "nuevo orden mundial" requiere trascender la visión más frecuente sobre este tema surgida del colapso del comunismo y de la Guerra del Golfo y enraizada, como quedó expresado, en la tradición norteamericana en los asuntos internacionales. A fin de ordenar el debate, me parece conveniente elaborar como punto de partida un sistema de preguntas que nos ayude a separar la paja del trigo en lo que hace a los aspectos efectivamente relevantes del orden emergente ${ }^{14}$ y nos permita, al mismo tiempo, eludir la sensación de estar transitando constantemente entre la esperanza y la decepción que suele producirnos la sucesión de acontecimientos de diferente signo que dan lugar tanto a la una como a la otra.

El sistema de preguntas debería centrarse en torno de tres macrocuestiones. La primera, y partiendo del concepto de orden mundial como configuración de las relaciones de fuerza, debería englobar el vasto conjunto de aspectos relativos a los rasgos que caracterizarían al nuevo orden mundial y a sus diferencias más notorias respecto del orden de la Guerra Fría. En breve, la pregunta básica aquí sería ¿qué puede apreciarse de "nuevo" en el "nuevo orden"? La segunda macrocuestión es la de los escenarios probables de orden mundial. Es decir ihacia dónde vamos? Interesa en este punto reflexionar esencialmente sobre el impacto de la nueva estructura sobre los procesos -esto es, sobre las relaciones entre las unidades políticas (medio interestatal) y entre los individuos y grupos (sociedad transnacional) y sus resultados-. Cabe en el marco de esta

\footnotetext{
${ }^{12}$ Hoffmann, Primacy or World Order..., op. cit., p. 190.

${ }^{13}$ Rosenau, op. cit, p. 4.

${ }^{14} \mathrm{Me} \mathrm{parece}$ más apropiado hablar de orden emergente que de nuevo orden mundial, dado que parto del supuesto de que el orden mundial se halla en una etapa de transición que durará un número importante de ax̂os. Así, en los pocos casos en que aparece en el texto la expresión nuevo orden debe equipararse a la de orden emergente:
} 
macrocuestión analizar las perspectivas de la política de orden mundial vis-à-vis la política como de costumbre. Por últỉmo, la tercera macrocuestión se refiere al impacto de las transformaciones en los cimientos del orden global sobre la naturaleza misma de las relaciones internacionales tal como se han dado hasta el presente. La pregunta esencial aquí sería ¿que hay de nuevo en las premisas que subyacen al orden emergente -en las "mentes y en los corazones" de los hombres, en palabras de Rosenau- respecto de las que sostuvieron a todos los órdenes anteriores o, en todo caso y para no ir tan lejos, desde Westfalia hasta el fin de la Guerra Fría? Según se aprecia, deberíamos ocuparnos bastante en este punto de las variables "blandas" de la política mundial, tales como los valores, las orientaciones, las predisposiciones, los sistemas de creencias y los hábitos de los gobernantes y de la "gente".

Desde luego, no pretendo -ni creo que pueda- responder a estas tres macrocuestiones. Sí procuro desarrollar, y de manera bastante esquemática, algunas ideas sobre cada una de ellas con el propósito de aportar elementos para el debate hoy en curso en América Latina sobre las transformaciones del ambiente internacional.

\section{Lo "nuevo" del "nuevo orden": estructura y procesos.}

Mis objetivos en este apartado son bastante modestos. Por una parte, intento señalar los rasgos principales de las fuerzas interactuantes en el orden emergente: ideas, recursos de poder e instituciones $y$, por otra, presentar algunas consideraciones referidas al impacto de la actual configuración de las relaciones de fuerzas entre los actores sobre los procesos. Me interesa muy especialmente ver si la nueva estructura histórica en formación facilita o no dar pasos en dirección del orden mundial como condición en el sentido de Hoffmann.

a. Las ideas y el nuevo orden. En relación con las ideas, entendidas como "imágenes colectivas de un orden social sustentadas por diferentes grupos de personas", ${ }^{15}$ el orden emergente presenta una importante atenuación del nivel de antagonismo que existía en el orden de la Guerra Fría respecto de la naturaleza fundamental de la

${ }^{15}$ Cox, op. cit, p. 218. 
política y de las relaciones internacionales, del rol del individuo en la historia, del carácter fundamental del enemigo, del significado de la justicia y del bien público, etc. Esta atenuación se debe no sólo a la defección de la ex-Unión Soviética y al colapso de las concepciones que sustentaban a los socialismos reales -lo que es obvio- sino también al debilitamiento relativo de los supuestos en los que se basaron los reclamos del "Sur" frente al "Norte", especialmente durante los años setenta. En efecto, las clásicas posiciones de confrontación entre ricos y pobres en la arena de las relaciones económicas internacionales parecen haber pasado de moda y haber sido reemplazadas por la búsqueda de consenso. ${ }^{16}$

Desde luego, esto no implica negar la importancia en cuanto a potencial de conflicto de otra clase de ideas rivales, tales los casos de los antagonismos nacionales y étnicos enraizados "en la historia y el recuerdo" y que han sido liberados por el "fin de la guerra ideológica" del viejo orden ${ }^{17}$ y el de un nuevo tipo de nacionalismo, que podríamos denominar "nacionalismo regional", visible tanto en Europa y Japón como en los Estados Unidos, aunque con menos intensidad en este último país. Los partidarios de este tipo de nacionalismo tienen dos cosas en común: a) poner el acento en las especificidades políticas, económicas, sociales y culturales de sus respectivos países y/o regiones, y b) destacan, por consiguiente, la necesidad de organizarse separadamente siguiendo los dictados estrechos del propio interés. Como se ha señalado, este nacionalismo regional es peligroso puesto que "puede destruir la coalición europea-japonesa-norteamericana que ganó la Guerra Fría y que es la mejor esperanza para un nuevo orden mundial. Puede asimismo convertirse en ... algo cercano al racismo". ${ }^{18}$

No obstante la importancia de estos conflictos, me parece que su envergadura no alcanza para impedir que el orden emergente transite de la heterogeneidad propia de la Guerra Fría hacia una condición sistemática de homogeneidad, dado que, como diría Aron,

\footnotetext{
${ }^{16}$ Que quede claro lo que se debilitó es el conjunto de supuestos a partir de los cuales la mayoría de los países đel Sur elaboró su libreto y sus políticas para manejar sus relaciones con el Norte y de ningún modo el conjunto de problemas normalmente englobađos en el ámbito de la ass llamada problemática Norte-Sur.

${ }^{17}$ Ver Arthur Schlesinger Jr., "La era de los conflictos raciales", El Cronista, 18 de diciembre de 1991, p. 18.

18 "The hole he left behind", The Economist, diciembre 21-enero 3 de 1991, p. 11. Ed comentario citado, que comparto, se inscribe indudablemente en la óptica del internacionalismo liberal.
} 
los principales Estados que lo componen "pertenecen a un mismo tipo y obedecen a un mismo concepto de la política". ${ }^{19}$ Por su parte, y ante el fracaso de las experiencias autoritarias (partidos únicos, autocracias militares o socialismos reales) y la pérdida de credibilidad de las peticiones "científicas" del marxismo-leninismo, una cantidad cada vez más importante de Estados ${ }^{20}$ medianos y pequeños reconoce los méritos de la democracia y del modo de producción capitalista. ${ }^{21}$

En este contexto, están dadas las condiciones para que las fuerzas que actúan en el nivel del sistema afecten de manera importante el comportamiento de los actores a través de lo que Waltz ha llamado la "socialización" (que limita y moldea el comportamiento) y la "competencia" (que lleva a que el comportamiento tienda a emular la "racionalidad" de los más exitosos). Ambas (socialización y competencia) son dos aspectos de un proceso mediante el cual la variedad de comportamientos y resultados tiende a reducirse. ${ }^{22}$

Podría acordarse también que la condición de homogeneidad sistémica favorece en principio la moderación en el comportamiento y una competencia más autocontrolada y menos destructiva. Ayuda, asimismo, a imponer límites a la violencia mediante la utilización de los mecanismos de seguridad colectiva que habían quedado congelados por la lógica de la Guerra Fría.

b. El nuevo orden y la cuestión del poder. La literatura especializada en relaciones internacionales se ha dedicado profundamente al tema del poder, que es naturalmente un concepto básico de la disciplina. Así, se ha escrito in extenso sobre cuestiones referidas a la

${ }^{19}$ Ver Raymond Aron, Pazy Guerra entre las Naciones, (Madrid: Alianza, 1985), Tomo I, p. 140.

${ }^{20}$ Digo Estados para simplificar el texto y no abrumaral lector con permanentes aclaraciones. En rigor, donde dice Estado debería leerse "los actuales gobernantes y una parte importante de la oposición y de la opinión pública de esos países".

${ }^{21}$ Debe notarse que đaigo modo đe producción capitalista y no capitalismo-liberal. Es altamente probable que el orden emergente esté caractcrizado no por el triunfo de este tipo de capitalismo sino por la rivalidad de distintas formas de capitalismo organizado y de mercado social que reserven a los Estados roles importantes. Esto se aplica tanto para los Estados capitalistas desarrollados como para los países subdesarrollados. Un interesante esbozo de este argumento, puede verse en James Kurth, "Things to Come. The Shape of the New World Order", The National Interest, Verano de 1991, pp. 3-12.

${ }^{2}$ Kenneth N. Waltz, op. cit, pp. 76-77. Advierto al lector que hago aquí una reinterpretación bastante libre de la teoría de Waltz, dado que la aplico tan solo al impacto de las ideas, entendidas como una de las fuerzas de la estructura, sobre el comportamiento de los actores. 
forma de medir el poder, a sus cambios de naturaleza, a su mayor o menor "fungibilidad", al problema de la conversión del poder potencial, tal como se lo mide por sus recursos, en poder efectivo, etc. Estos escritos muestran grandes diferencias entre los autores dado que el poder en la política internacional -y me valgo de palabras de Nyees, al igual que el amor, más fácil de experimentar que de definir, medir o entender. ${ }^{23}$ Hago esta primera referencia al tema del poder para poner de manifiesto que es poco útil a fines prácticos y además incorrecto, pretender predecir probables comportamientos a partir de juicios (o prejuicios) basados en análisis simplistas de la distribución global del poder y desde allí sostener ligeramente cosas tales como que el orden mundial hoy vive un "momento de unipolaridad" 24 y que vamos hacia una nueva era de Pax Americana, o por el contrario que Estados Unidos declina irremediablemente y que habrá, por ejemplo, una Pax Nipona o, en defecto de una u otra, una Pax Consortium, ${ }^{25}$ y así. Sin negar la "parte" de verdad que pueda tener este tipo de lugares comunes, lo que propongo es establecer algunos criterios un poco más finos sobre la cuestión de la distribución del poder en la post-Guerra Fría, para lo cual también conviene tener presente la distinción analítica entre medio interestatal y sociedad transnacional a la que hice referencia anteriormente.

A ese fin, creo importante apelar a las dos concepciones tradicionales sobre la forma de medir el poder -esto es, como conjunto inicial de atributos que da al actor una capacidad de acción potencial y como influencia efectiva sobre patrones de resultados-. La primera aproximación, propia de las escuelas tradicionalistas en la disciplina, sirve para conocer la estructura de poder global de la política mundial, aunque por lo general es poco adecuada para predecir patrones de resultados. ${ }^{26}$ La segunda ayuda a comprender los problemas relativos a la conversión de los recursos disponibles en poder concreto y a penetrar la compleja urdimbre del linkage politics.

\footnotetext{
${ }^{23}$ Joseph S. Nye, La naturaleza cambiante del poder norteamericano, (Buenos Aires: Grupo Editor Latinoamericano), 1991, p. 35.

${ }^{24}$ Charles Krauthammer, "The Unipolar Moment", Foreign Affairs, America and the World 1990-91, vol. 70, №1, 1991.

${ }^{25}$ Acerca de la idea de una Pax Consortium, ver Yasuhiro Nakasone, "El error del pacifismo japonés", Clarłn, 21 de mayo de 1991, p. 15.

${ }^{26}$ Utilizo en este trabajo "estructura de poder global" y "estructura de poder por áreas de cuestiones" en el sentido de Robert $\mathrm{O}$. Keohane y Joseph S. Nye, Power and Interdependence. World Politics in Transition, (Boston: Harvard University Press, 1997), capítulo 3.
} 
Si se trata de contabilizar recursos no puede discutirse que la estructura "horizontal" del actual medio interestatal es multipolar, aunque con polos que reúnen distintos atributos de poder. ${ }^{27}$ Estados Unidos es el único polo que agrupa atributos militares y económicos, Alemania y Japón atributos económicos y financieros y la hoy llàmada Comunidad de Estados Independientes atributos sólo militares. Desde esta perspectiva, el nuevo orden sería tripolar ${ }^{28}$ o cuadripolar y también lo sería si trabajáramos con unidades de análisis que superan el Estado-nación: la mencionada Comunidad de Estados Indépendientes, el bloque comercial de América del Norte (Estados Unidos, Canadá y México), la Comunidad Europea, con o sin liderazgo alemán, y Japón junto a China y a los tigres asiáticos. Sin embargo, debe recordarse que también se hablaba de multipolaridad -y acertadamente- en el orden de la Guerra Fría cuando se analizaba la distribución del poder en términos económicos. Por lo tanto, hablar hoy de multipolaridad a secas no nos ayuda mucho para detectar nuevos rasgos del orden emergente. En consecuencia, es preciso calificar el concepto de multipolaridad.

Primero, corresponde notar el cambio de sentido de la multipolaridad como resultado del fin del conflicto hegemónico entre Estados Unidos y la ex-Unión Soviética. La anterior multipolaridad (económica) tenía lugar en el marco de un sistema ideológicamente heterogéneo y bipolar desde el punto de vista estratégico-militar. Alemania y Japón eran grandes potencias económicas pero su seguridad dependía de Estados Unidos. Según la aguda observación de Tucker: "Mañana, estos Estados serán grandes poderes no sólo en el sentido en que ya lo han sido por algún tiempo; ellos serán grandes poderes en el sentido de que el impacto político de su poder económico no estará más calificado por una dependencia de seguridad que les imponía constreñimientos sustanciales a su libertad de acción en materia de política exterior" ${ }^{\mathrm{29}}$ Así, cabría esperar nuevos y ampliados

\footnotetext{
${ }^{27}$ Digo estructura horizontal porque lo único que importa para una tipología de sistemas es el número de grandes poderes.

. ${ }^{28}$ La disolución de las Fuerzas Armadas soviéticas y la disgregación de sus antiguos componentes en los nuevos Estados que forman la precaria Comunidad de Estados Independientes, aunadas a la crisis política y económica de todos ellos, llevará probablemente a que la estructura de poder del orden emergente sea tripolar desde el punto de vista horizontal.

${ }^{29}$ Robert Tucker, "1989 and All That", Foreign Affairs, Otoño 1990, pp. 96-7.
} 
roles políticos, globales y especialmente regionales, de parte de estos dos Estados en ascenso. ${ }^{30}$

Segundo, es preciso observar el cambio producido en la naturaleza de la competencia básica en el nuevo orden mundial. Durante la etapa de la Guerra Fría, la rivalidad Este/Oeste se fundaba en el sentido de misión de cada una de las partes que decían representar un modelo para el futuro de la humanidad. Había en esta disputa componentes esencialmente políticos, militares e ideológicos. Actualmente, la competencia tiene otras características. Los poderes en ascenso no presentan amenazas militares -a diferencia de lo que sucediera en todas las otras transiciones de orden mundial-. En palabras de Pfaff, la competencia "todavía concierne a la influencia nacional, pero una influencia que se obtiene a través del éxito comercial y el liderazgo industrial y científico, produciendo prosperidad y bienestar nacional". ${ }^{31}$ En este marco, los nuevos rivales desplegarán sus armas y librarán sus batallas en el campo de Mercurio y no en el de Marte. Así, su comportamiento estará probablemente mucho más cerca del tipo ideal "Estado comercial" que del tipo "Estado político-militar-territorialista" y, por consiguiente, procurarán fortalecer su poder político a través del incremento de la fortaleza económica y no del poder militar. ${ }^{32}$

Tercero, es necesario distinguir polaridad de polarización. En el modelo de estructura de poder global la noción de polo designa a los grandes poderes de una era. Su número es el que lleva a los analistas de la política internacional a realizar distinciones entre los sistemas internacionales. Así, según la cantidad de grandes poderes hablamos de sistemas bipolares o multipolares. El término polarización, en cambio, se refiere a otra condición sistemática: la propensión de los actores a agruparse en torno de los polos. Un sistema, bipolar o multipolar, tiende a la polarización (y puede hacerse polarizado) cuando los grandes poderes forman bloques cuyas interacciones externas se caracterizan por crecientes niveles de conflictos mientras

\footnotetext{
${ }^{30}$ Acerca de la "discontinuidad" de rol de los polos en ascenso, ver el reciente trabajo đe Yoichi Finabashi, "Japan and the New World Order", Foreign Affairs, Invierno 1991/92, y la opinión đe Jacques Delors en "Europe's Ambitions", Foreign Policy, Otoño 1990.

${ }^{31}$ William Pfaff, "Redefining World Power", Foreign Affairs. America and the World 1990191, p. 37. Para este autor -juicio que comparto- otro efecto fundamental del fin de la rivalidad bipolar es la desaparición de la categotía superpotencia.

${ }^{32}$ Acerca de estos dos tipos ideales de Estados, ver Richard Resecrance, The Rise of the Trading State, (Nueva York: Basic Books, 1986), pp. 22-44.
} 
que las internas se hacen más cooperativas. ${ }^{33}$ Conforme a esta dinámica los sistemas polarizados reducen significativamente las oportunidades de interacción a escala "mundial". La pregunta que cabe aquí no es entonces, y como suele hacerse, si el orden emergente será unipolar o multipolar -algo que, como quedó dicho está fuera de discusión-, sino si la multipolaridad que lo caracteriza tenderá o no a la polarización. Esta cuestión nos remite directamente a uno de los temas que despierta mayores preocupaciones tanto en esferas académicas como gubernamentales: si los tres polos tendrán la capacidad de mantener una relación cooperativa y flexible y, en definitiva, provechosa para el orden como condición o si, por el contrario, se polarizarán dando lugar a la formación de un escenario global fragmentado e inestable, signado por políticas neomercantilistas y guerras comerciales.

Cuarto, cabe apuntar que si bien es cierto que el conocimiento de la distribución global del poder es un punto de partida irreemplazable para predecir probables comportamientos y resultados, la medición de grados de poder computando meramente recursos poseídos (poder potencial) dice realmente poco sobre la capacidad de los países de traducir esos recursos en resultados deseados (poder efectivo). Tampoco informa sobre los cambios que se producen en la naturaleza del poder y que influyen en su mayor o menor productividad. ${ }^{34}$ Además, el acento excluyente en la estructura horizontal del poder ignora o minimiza el fenómeno de la difusión vertical del poder. Si nos proponemos identificar polos aplicando los modelos de estructura de poder por áreas de cuestiones o de regímenes internacionales $^{35}$ nos encontraremos, seguramente, con una cartografía distinta a la que ofrece el modelo de la estructura de poder global. En el primer caso, la "multipolaridad" será mucho más amplia, fluida, diferenciada y heterogénea que la del segundo. En realidad sería más

${ }^{33}$ Ver Charles W. Kegley, Jr. y Gregory A. Raymond, "Normative Underpinnings of Superpower Peace in a Multipolar World", trabajo preparado para el XV Congreso de la Asociación Internacional de Ciencia Política, Buenos Aires, julio 19-26 de 1991, p. 15.

${ }^{34}$ Acerca de la nueva productividad del poder, ver Hoffmann, Stanley, "A New World and its Troubles" ${ }^{*}$ Foreign Affairs, Otoño 1990, p. 121.

${ }^{35}$ Uso el concepto "regímenes internacionales" en el sentido de Stephen D. Krasner -esto es, como conjuntos implícitos o explícitos de principios, normas, reglas y procesos de toma de decisiones alrededor de los cuales convergen las expectativas de los actores en una área dada de las relaciones internacionales-. Ver su trabajo "Structural causes and regime consequences: regimes as intervening variables", en: Stephen D. Krasner (ed.), Intemational Regimes, (Ithaca y Londres: Cornell University Press, 1983), p. 2. 
apropiado hablar aquí de policentrismo que de multipolaridad. Esto último, sugiere además la necesidad de replantearnos en este nivel de análisis la concepción misma de polo e igualmente las de centro y periferia tal como se las concibiera en los años del orden de la Guerra Fría.

El cambio de sentido de la multipolaridad, la transformación de la naturaleza de la competencia básica y la mayor difusión horizontal y vertical del poder tanto entre actores como en áreas de cuestiones, nos conducen, en último lugar, a la espinosa cuestión del liderazgo del orden mundial. Como es sabido, la preocupación académica y política por el tema del liderazgo y sobre la relación entre liderazgo y estabilidad es de antigua data en la disciplina, y se acentúa a partir de los años setenta cuando se abre en los Estados Unidos el debate sobre la declinación relativa del poderío global norteamericano visà-vis los otros dos polos del capitalismo desarrollado.

Con este telón de fondo, en un famoso trabajo publicado en el año 1974, Kindleberger insistía que el liderazgo internacional, para ser efectivo, debía tener un estabilizador y no varios. ${ }^{36}$ Tres años después, en un trabajo tan famoso como el anterior, Keohane y Nye reconocían, en cambio, que en las condiciones de interdependencia compleja el único liderazgo efectivo era el multilateral, tanto a escala global como en la distintas áreas de cuestiones. ${ }^{37}$ Según ellos, la era de los liderazgos hegemónicos y unilaterales había llegado a su fin.

Salvo contadas excepciones, el grueso de los analistas de las relaciones internacionales ha tendido a coincidir con esta segunda opinión. Así, una y mil veces se señaló que Estados Unidos carecía tanto del poder como del will para asumir y ejercer un rol de liderazgo hegemónico o unilateral. También se dijo que la estabilidad mundial, al menos en la arena de las interdependencias económicas, dependería cada vez más de lo que hicieran Estados Unidos, Japón y la Comunidad Europea, particularmente Alemania. Desaparecida la Unión Soviética, estas opiniones parecen hoy más válidas que nunca.

Si se acepta en principio que el único tipo de liderazgo efectivo en el orden emergente es el multilateral cabría hacer al menos tres preguntas: ¿quienes estarán a cargo? ¿dónde se ejercerá? y ¿en qué

\footnotetext{
${ }^{36}$ Charles Kindleberg, The World in Depression, 1929-39, (Berkeley: University of California Press, 1974), p. 305.

${ }^{37}$ Robert O. Keohane y Joseph S. Nye, op. cit, p. 229.
} 
forma? ${ }^{38}$ La respuesta a las dos primeras preguntas dependerá en buena medida del nivel de análisis que se utilice. El quién y el dónde parecen bastante claros sise adopta el modelo de estructura de poder global. No lo es para nada si nos movemos dentro de los marcos propuestos por los modelos de estructura de poder por áreas temáticas y de regímenes internacionales. En relación con la tercera pregunta, el carácter multilateral del liderazgo debería tender en principio a que prevalezca la inducción por encima de la imposición. Esto requiere, naturalmente, que los lideres sacrifiquen algunos "intereses nacionales" y algunas ganancias de corto plazo en beneficio de los intereses y la estabilidad globales y, al mismo tiempo, que los liderados no se comporten como free riders. Esta cooperación, a su vez, dependerá de la legitimidad del liderazgo -esto es la percepción extendida de que el mismo se ejerce en interés de todas las partes-.. ${ }^{39}$

c. Las instituciones y el nuevo orden. Cabe aquí señalar dos aspectos de importancia para el debate. Primero, es preciso tener en cuenta que el concepto institución ha sido utilizado en la literatura y en la práctica de manera vaga y confusa, dado que se denomina "instituciones" a muchas cosas diferentes. A los fines de nuestro análisis, me parece útil señalar, siguiendo a Keohane, que el término "institución" puede referir tanto un patrón general o categorización de actividad (por ejemplo, la soberanía estatal, el equilibrio del poder, los mecanismos diplomáticos o la neutralidad) como "particular human-constructed arrangements", formal o informalmente organizados (por ejemplo, el Estado argentino, las Naciones Unidas, el GATT, el régimen de no proliferación o los acuerdos de integración argentinobrasileños). Lo que ambas referencias tienen en común es que "reúnen el criterio para una amplia definición de instituciones: las dos involucran conjuntos de reglas -formales e informales- que prescriben roles, constriñen la actividad y forman las expectativas" ${ }^{40} \mathrm{Cuan-}$ do se hace referencia a las instituciones de los órdenes mundiales se alude por lo general a las del segundo tipo, es decir a instituciones

\footnotetext{
${ }^{38}$ Desde una posición más extrema algunos autores colocan una pregunta previa a las que acabo de hacer. Según Gardner la pregunta clave no sería "quién estaráa a cargo" de establecer e imponer las reglas de juego del mundo de la post-Guerra Fría, sino más bien "si alguien lo estará. Ver su op. cit, p. 24.

${ }^{39}$ Keohane y Nye, op. cit, p. 231.

${ }^{40}$ Robert O. Keohane, International Institutions and State Power. Essays in International Relations Theory, (Boulder. Westview Press, 1989), p. 162.
} 
específicas, identificables en el tiempo y el espacio, y que tienen, por tanto, una única y determinada vida histórica. Estas instituciones ejemplifican usualmente patrones generales de actividad. ${ }^{41}$ Así, la Sociedad de las Naciones o las Naciones Unidas son ejemplos de diplomacia multilateral, los recientes acuerdos argentino-brasileños de diplomacia bilateral, el Estado argentino de la soberanía estatal). Hecha esta aclaración, nuestro objetivo en este punto debería ser la identificación de las instituciones específicas claves del orden emergente y el análisis de su probable rol. No obstante ello, y teniendo en cuenta los cambios de cimientos que menciono en el apartado III, creo importante que consideremos también en el debate el impacto de esos cambios sobre la soberanía estatal que es un patron general "institucionalizado" de actividad en práctica desde hace tres siglos.

En segundo lugar, es necesario recordar que las instituciones reflejan, al menos en el momento de su creación, las relaciones prevalecientes de poder, y que tienden en un principio a alentar imágenes colectivas consistentes con esas relaciones. ${ }^{42}$ Dado que el paso del orden de la Guerra Fría al nuevo orden nos coloca en un momento de transición en el sistema internacional comparable a la conclusión de una gran guerra, cabe esperar la creación de nuevas instituciones que reflejen la nueva distribución del poder global y por temas, la readaptación de muchas de las existentes a las nuevas realidades, y la desaparición de otras tantas que fueron claves en el orden anterior y que han perdido el sentido que les dio origen. Debe recordarse, asimismo, que la rélación causal entre distribución de poder e instituciones suele cambiar a lo largo de la vida de estas últimas, ya que las instituciones y la distribución de poder no cambian a la misma velocidad, siendo las primeras más durables que la segun$\mathrm{da}^{43}$

La condición sistémica de homogeneidad hace abrigar esperanzas de que se amplíe el papel y las funciones de las instituciones. A su vez, la difusión del poder y los nuevos desafíos globales del orden mundial requieren (y hacen deseable) que los intereses de múltiples actores se canalicen y negocien a través de los regímenes internacionales.

\footnotetext{
41 Ibid

${ }^{42}$ Cf. Cox, op. cit, p. 219.

${ }^{43}$ Acerca de la importancia de la periodización de la vida de las instituciones, ver Stephen D. Krasner, "Regimes and the limits of realism: regimes as autonomnous variables", en: Stephen D. Krasner (ed.), op. cit, pp. 357-8.
} 
Por cierto, las medidas adoptadas por Naciones Unidas ${ }^{44}$ para preservar o restaurar la paz en diversas áreas conflictivas del mundo y las llevadas a cabo por instituciones tan variadas como la OEA en Haití o la Comunidad Económica de Estados de Africa Occidental en Liberia para buscar soluciones negociadas a conflictos internos, son ejemplos auspiciosos del papel positivo que pueden llegar a desempeñar las instituciones específicas de diplomacia multilateral en el orden emergente. ${ }^{45}$ Estos primeros pasos permiten conjeturar que en el campo de la guerra y de la paz existen buenas perspectivas de avanzar un poco en dirección del orden mundial como condición. Lamentablemente, esto no está tan claro en la arena de las relaciones económicas internacionales o en las cuestiones que ocupan un lugar destacado en la agenda internacional tales como medio ambiente, narcotráfico o migraciones. ${ }^{46}$

d. Orden mundial y sociedad tramsnacional. Hasta aquí mis reflexiones se han referido esencialmente a la compleja trama del orden emergente en lo que hace al medio interestatal. El corte de la realidad de la sociedad transnacional tampoco es una tarea sencilla. Según donde cortemos veremos o daremos prioridad a aspectos diferentes. Sin embargo, hay tres cosas muy claras que deberíamos tener en cuenta para ordenar nuestro debate sobre este punto. Por un lado, que las relaciones transnacionales seguirán operando dentro de un marco limitado y condicionado por las reglas establecidas por los Estados preponderantes; sea en la estructura de poder global, sea en las estructuras de poder por áreas temáticas. Por otro lado, y en estrecha relación con el punto anterior, que la vitalidad de la sociedad transnacional dependerá de la mayor o menor libertad de los inter-

\footnotetext{
44. Sobre las posibilidades de Naciones Unidas de ejercer un nuevo rol en el orden emergente, ver Bruce Russett y James S. Suterlin, "The U. N. in a New World Order", Foreign Affairs, Primavera 1991, pp. 70-83.

${ }^{45}$ En poco tiempo, casi 50.000 cascos azules estarán cumpliendo misiones de paz en diversos lugares del mundo que van desde Yugoslavia a Camboya y el Sahara Occidental. Muy probablemente, y con grados variados de asistencia, el rol de Naciones Unidas será clave para mantener la paz en los casos de conflictos no sólo de naturaleza interestatal, sino también en los de naturaleza civil. De este modo, el papel de la Organización se expandirá de lo puramente intergubernamental (plano en el que ha sido poco efectiva) a otro de preservación de la paz dentro de los Estados. Aun más, este rol puede llegar a ser el de protector đe pueblos oprimidos contra sus propios gobiernos.

${ }^{46}$ Acerca de las dificultades que rodean a estas cuestiones, ver mi trabajo "La agenda global en los años '90: antiguos y nuevos temas ${ }^{n}$, en Roberto Russell (comp.), La agenda intemacional en los años '90, (Buenos Aires: Grupo Editor Latinoamericano, 1990), pp. 13-36.
} 
cambios, de las migraciones y de las comunicaciones, de la fortaleza de las creencias comunes y del número y eficacia de las instituciones. ${ }^{47} \mathrm{Y}$, por último, que las relaciones transnacionales se desenvolverán en un medio caracterizado por la expansión de la producción internacional y de los mercados. Como lo expresara Cox: "La producción internacional juega hoy el rol formativo en relación con la estructura de los Estados y del orden mundial comparable al que jugara la manufactura nacional y el capital comercial a mediados del siglo diecinueve". ${ }^{48}$

En este marco, cabe preguntarnos sobre las modalidades que: adoptarán las relaciones entre los grupos y los individuos a través de las fronteras y, muy especialmente, sobre el impacto del proceso de producción sobre la forma de los Estados y el futuro del orden emergente. También sobre el rol que desempeñarán los actores no estatales en la adopción de decisiones sobre cuestiones de naturaleza global, tales los casos del medio ambiente, la pobreza, el narcotráfico o las migraciones, para citar tan sólo a las más notadas.

\section{El cambio de esencias o la primera vez.}

El fin de la Guerra Fría ha reflotado y fortalecido un debate entre los analistas que no se limita a los cambios en la estructura del orden mundial y a su impacto probable sobre los procesos. El mismo tiene un contenido más profundo, dado que se refiere a la naturaleza misma de las relaciones internacionales.

Los más reacios a aceptar todo cambio de "esencias" en esa naturaleza reiteran -y advierten- que no deben esperarse (ni cabe esperar) alteraciones sustanciales en la conducta de los Estados. ${ }^{49}$ Con su vista puesta en la historia, recuerdan que, con o sin Guerra Fría, los Estados seguirán comportándose conforme a los supuestos básicos de la teoría realista. ${ }^{50}$ Como siempre, insisten en la continui-

\footnotetext{
${ }^{47}$ Ver Aron, op. cit, p. 146.

$43 \mathrm{Cox}_{j}$ op. cit. p. 233.

${ }^{49}$ Para salir al cruce de los "nuevos idealistas", el conocido pensador neoconservador Irving Kristol señaló poco después de desatađa la Guerra del Golfo que "no va a haber un nuevo orden mundial, tan sólo el viejo desorden mundial en nuevas configuraciones". Ver su artículo "After the War, What?", Wall Street Journal, 22 de febrero de 1991, PSI. 21.

${ }^{50}$ Acerca de los supuestos de la teoría realista, ver Morgenthau, Hans J., Polftica entre las naciones. La lucha por el poder y la paz, (Buenos Aires: Grupo Editor Latinoamericano, 1986), pp. 11-26.
} 
dad "suprahistórica" de la lucha por el poder y en la reiteración de los equilibrios de poder. Así, desconfían profundamente (y descreen) de las políticas de orden mundial y de los mecanismos de seguridad colectiva. Para ellos, la paz, siempre precaria, sólo se logra y asegura con la espada. Todo los demás es ingenuidad o lisa ignorancia de la naturaleza humana, cuyos elementos esenciales, y por lo tanto inmutables, serían el miedo, el egoísmo y el deseo de poder. Estos tres aspectos, enraizados en el hombre serían más importantes para explicar el conflicto internacional que la escasez económica, el imperialismo o la ausencia de un árbitro supremo.

A la inversa, otros analistas, no necesariamente inscritos en el paradigma idealista, enfatizan "el advenimiento de la discontinuidad" en los asuntos internacionales ${ }^{51}$ y opinan que por primera vez en la historia de la humanidad estaríamós en una suerte de casa a mitad de camino entre el gobierno mundial y el estado de naturaleza. ${ }^{52}$ Aunque con distintos énfasis, quienes se sitúan en esta vereda afirman que por diversas razones -sea por "aprendizaje evolutivo", 53 o por "transformaciones en los parámetros de las relaciones internacionales" $-{ }^{54}$ los cimientos de la política mundial se han alterado en forma cualitativa. Esta alteración se pone de manifiesto en las transformaciones que se habrían producido en las principales metas y dilemas de los actores, sus prioridades normativas, los modos de colaboración, el alcance de la agenda de política exterior, el locus del liderazgo. ${ }^{55}$ En este marco, el mundo de la política mundial ya habría dejado de ser Estado-céntrico para convertirse en un mundo multicéntrico, en el que el número de actores esenciales se contaría por miles.

\footnotetext{
${ }^{51}$ Hoffmann, Stanley, "A New World and its Troubles", op. cit, p. 121.

${ }^{52}$ Escapa a mi propossito ocuparme aquí de los factores que indicarían el mencionado cambio de naturaleza. Una buena síntesis de algunos de los argumentos que van en esa línea puede verse en Robert Gilpin, War and Change in World Politics, (Cambridge: Cambridge University Press, 1981), pp. 211-230.

${ }^{53} \mathrm{Ver}$ al respecto el interesante artículo de George Modelski, "Is world politics evolutionaty learning?", International Organization, Inviemo 1990, pp. 1-24.

${ }^{54}$ Rosenau, op. cit., p. 4

${ }^{55}$ Para un detaile sobre los cambios cn cada uno de estos puntos, ver ibid. pp. 10-11.
} 


\section{Consideraciones finales.}

La historia de las relaciones internacionales nos enseña a ser cautelosos. Conflictos de todo tipo, "ideologías de exclusión ${ }^{\text {"56 }}$ fundadas en el resentimiento, el odio y el temor, los sentimientos "tribales", los intereses estrechos y de corto plazo, las tremendas desigualdades en la distribución de los bienes, forman hoy, como siempre, una parte esencial de la trama de la política mundial.

Por otro lado, esta misma trama muestra algunos signos que permiten sostener que la humanidad, a pesar de todo, camina tímidamente (aunque por supuesto no en forma lineal) en dirección de la utopía de Kant. O, al menos, que tiene posibilidades de hacerlo y que, por tanto, no está forzosamente condenada a repetir el pasado.

Esta puja clásica entre los elementos de signo opuesto de la trama internacional resulta en este momento acaso más nítida que nunca. Los signos de contenido positivo (vbg. homogeneidad sistémica, interdependencia creciente, fortalecimiento y mayor efectividad de la diplomacia multilateral) conviven con guerras y conflictos diversos, situaciones ampliadas de miseria y extrema pobreza, distintas formas de terrorismo, rebrotes proteccionistas, etc. Munidos de los signos positivos, y sin ignorar los negativos, muchos analistas creen que la humanidad dispone de una oportunidad inédita para despojarse de los errores y calamidades del pasado y para erradicar, definitivamente, el fantasma de la guerra global. Otros, por su parte, desestiman estas esperanzas de cambio y presentan para justificar sus argumentos una larga lista de hechos cotidianos que se inscriben en la política mundial como de costumbre. Algunos casos, como la guerra en Yugoslavia o la recomposición de Mitteleuropa bajo la hegemonía alemana, les dan pie para señalar que lo que cabe es hablar de "retorno" y no de "fin de la historia".

La fluida e incierta sucesión de acontecimientos de signo contrario ha llevado a numerosos autores a describir el mapa geopolítico de la post-Guerra Fría como una confrontación entre fuerzas de integración y de fragmentación del ambiente internacional (ej. fuerzas que favorecen la globalización de la economía vs. las que defienden políticas más proteccionistas, ideologías universalistas vs. los distintos tipos de nacionalismos). ${ }^{57}$ Esta simplificación deliberada de

\footnotetext{
${ }^{56}$ Tomo esta expresión de Delors, op. cit, p. 16.

${ }^{57}$ Ver, por ejemplo, John Lewis Gaddis, "Toward the Post-Cold World Order", Foreign Affairs, Primavera 1991.
} 
la política mundial es útil como recurso heurístico para analizar los procesos del orden mundial. Sin embargo, parece conveniente, y también con fines analíticos, agregar a este enfrentamiento de fuerzas opuestas las inconsistencias que resultan de la brecha temporal existente entre los cambios de cimientos del orden global y las posibilidades concretas de adoptar políticas acordes con esos cambios. Esta segunda cuestión tiene que ver con el lado evolutivo del orden mundial. Cuanto mayor sea la distancia que separa los cambios de las políticas menos nos moveremos en dirección del orden mundial como condición. Por cierto, la dilatada extensión que hoy caracteriza a esta brecha juega por ahora a favor de quienes sostienen que en esencia no habrá nada de nuevo bajo el sol del "nuevo orden mundial". 